\title{
A COACHING-BASED FRAMEWORK FOR INDIVIDUAL CONSULTATIONS
}

Deandra Little, Michael S. Palmer, University of Virginia

Educational developers committed to promoting effective teaching and learning practices often make the same mistake we advise instructors to avoid: privileging content over process in individual consultations. We describe a process-oriented consultation model based on effective practices from the literature on individual consultations, coaching, learning, and motivation. Using this three-step model, educational developers can systematically create a collaborative environment that is nonjudgmental and nonprescriptive and draws on the client's capabilities, experiences, aspirations, and resourcefulness.

When Michael was on leave, Deandra consulted with a faculty member he had worked with extensively over the previous three years. During that time, Karen (not her real name) had gradually begun to incorporate student-centered teaching methods into her courses. That day's discussion of various ways to make her lectures more interactive seemed fairly straightforward; however, Karen's concluding remark suggested she valued it for more than just the ideas she left with: "I enjoy working with folks from your center. You ask good questions that help me see what is already there." It was clear that she was responding to the coachingbased framework we both use in individual consultations. Her remarks underscored what we have experienced with other faculty and graduate instructors: the process, as much as the content, matters in consultations. Often it can be difficult to find the right balance between the two. We frequently hear this concern echoed by other educational developers. Ironically those of us committed to promoting effective teaching and learning practices often find ourselves inadvertently making the same 
mistake we advise the instructors we work with to avoid: focusing on content delivery rather than on engagement and learning.

In an attempt to keep consultations process oriented and collaborative, in 2005 we adopted a three-step coaching framework that includes best practices from literature on instructional consultations, coaching, learning and motivation theory, question asking, and active listening. It organizes effective consultation strategies into a heuristic with three interrelated components: deep listening, asking powerful questions, and prompting action. We find that using this consultation framework reminds us of the importance of inclusion, relevance, and autonomy for motivation and learning (Svinicki, 2004; Theall, 2001). Moreover, it provides a language and systematic structure for consultations that is aligned with the literature on effective consultation (Brinko, 1993; Brinko \& Menges, 1997; Gillespie, Hilsen, \& Wadsworth, 2002; Knapper \& Piccinin, 1999; Lewis \& Lunde, 2001).

We became interested in professional coaching techniques because they emphasize interactions that are nonprescriptive, instructor centered, goal based, and action oriented. Coaching models focus on promoting professional or personal development through facilitated discussion (Costa $\&$ Garmston, 1994; Stober \& Grant, 2006) and incorporate principles of knowledge construction and adult learning theory (Brookfield, 1986; Cranton, 2006). We also found basic metaphors for coaching that aptly described the educational developer's role in consultations. In consultations, developers help move or convey (Costa \& Garmston, 1994) instructors from one point to another. Or, to use another metaphor, developers, like coaches, work as catalysts for change.

We use the coaching framework in our own consultations, our training of faculty and graduate student consultants, and a number of workshops for new and experienced educational developers. In these settings, coaching strategies have helped both consultant and instructor "see what is there" by reminding us to keep the focus trained on the individual, including his or her understanding of the issues, and readiness for and motivation to change.

\section{Individual Consultations: Opportunities and Challenges}

In spite of a good deal of variation in the conditions of educational development work-whether working alone or as part of a center or system, whether full or part time-individual consultations make up a large part of the workload. Depending on how the position is defined, educational developers may consult with faculty, graduate and professional students, administrators, and 
support staff, among others. The literature on instructional consultations suggests they are "the most promising way of fundamentally changing postsecondary teaching" (Brinko, 1997, p. vii) and "the best way to instill lasting commitment to and change in a faculty member's teaching" (Lewis \& Lunde, 2001, p. iii). In short, individual consultations are at their core about learning and transformation-changing perspectives and practices to improve student learning, create opportunities for instructors to explore and further their own goals for teaching or professional development, and even, at times, help administrators anticipate and respond to changes in ways that promote the core institutional mission.

One way to think about the variety and complexity of educational development is to consider the specific tasks or roles involved in working with individual instructors. Lewis (2002) organizes the tasks into distinct categories: collecting and managing data, providing information and support, and serving as facilitators and sometimes even counselors. Clearly these tasks require a range of skills, including providing empathy and positive reinforcement, recognizing institutional support structures and cultures, identifying and summarizing the literature, and analyzing data and motivating change. For new developers and experienced faculty members alike, trying to manage these can seem overwhelming, particularly given that as a whole, developers "receive little systematic training for their role-an irony, because the lack of training in teaching for faculty is the very reason such consultation is needed in the first place" (Knapper \& Piccinin, 1999, pp. 4-5).

Tiberius, Tipping, and Smith (1997) posit that developers can be effective outside their range of expertise by focusing on problem solving. Such a process-oriented framework can help beginning developers address teaching problems or scenarios new to them. One former graduate student consultant at our center explained that being trained to use the process-oriented framework changed the way she viewed the consultant's role: " $\mathrm{My}$ job is not to tell the instructor my ten ideas for how to improve his or her teaching. Rather, my job is to be a listener, to offer suggestions when asked for, but primarily, to help the instructor think, reflect, and decide for him- or herself how to improve teaching. This was hard to do at first, but ultimately, it was freeing."

More experienced developers face a related but different challenge: how to manage multiple roles while navigating the tension between knowledge of teaching and learning practices and the urge to provide solutions. For such developers, a coaching framework can be a useful cue to remain mindful of how our practices enact our intentions, to listen first, and to be aware of when and how we intervene during a consultation. 


\section{Deep Listening}

Listening, specifically listening attentively and with empathy, is key to a successful consultation. This observation may seem self-evident, but the difficulty and value of deep listening can easily be underestimated. As Brinko (1997) notes, our reported behavior may differ greatly from our observed behavior in the consultation setting; we may think we are listening more and talking less than we actually do. Focused, empathetic listening can be difficult to sustain, yet it is often key to effective consultations. Garmston and Wellman (1999) describe several types of listening that can hinder collaboration and learning. Building on their work, we have found that categorizing different types of listening according to their focal point-the listener-developer, the problem, or the speaker-instructorhelps us consider whether our listening habits facilitate learning.

In the first category, listener- or self-focused listening, the consultant listens to the words but focuses only on what they mean to him or her. This may take any of the following forms: distracted listening, or pretending to listen while focused on other thoughts; autobiographical listening, or shifting the focus from speaker to listener; interruptive listening, or stopping the speaker impatiently to focus on the listener's ideas; and inquisitive listening, or listening with self-serving curiosity. We might, for example, find ourselves listening in a self-focused way when we ask questions about the content of a course because it overlaps with our own interests or when we interrupt to relate similar situations.

In the next category, what we term problem-focused listening, the listener pays close attention to the words being spoken but lacks an awareness of the context and is inattentive to the speaker's nonverbal cues. Examples include editorial listening and solution listening. Editorial listening is just that-playing editor to the speaker's words by interrupting to correct, revise, or finish the speaker's sentences. Often when we listen in this way, we mentally make judgments about the speaker or situation rather than paying attention to nonverbal cues or how the listener expresses his or her feelings or values. Another form of problem-focused listening, solution listening, can be a trap into which many of us fall in spite of our best intentions. As educational developers who want to help instructors solve their problems, we often begin to provide answers or offer advice without hearing the full scope of the problem or allowing the speaker to begin addressing answers on his or her own.

In daily interactions, we often move between types of listening depending on our mood, energy level, attachment to the topic or person, or the situation. There are times, for example, when solution listening is called 
for. For instance, if institutional policies are clearly involved, there may be only one possible answer. Similarly there are times when inquisitive or autobiographical listening allows us to connect with the speaker or begin to build rapport. In general, however, self- and problem-focused listening result in less effective consultations because they introduce digressions, shift the focus away from the speaker, and can create a didactic rather than a dialogic relationship.

In the coaching framework, the developer strives for the third category: speaker-focused or deep listening. We describe deep listening as a form of empathetic communication similar to that central to social work (Rhoedick, 2006) and other helping professions. Empathetic communication is more than just mirroring the speaker's words; it engages both affective and cognitive processes in an effort to see the world from the other person's perspective (Stober, 2006). Identifying the speaker's feelings and communicating an understanding of them helps reduce perceived threats and defensiveness, while creating an atmosphere conducive to behavior change (Rhoedick, 2006). Our experience using deep listening mirrors the findings of psychotherapists and coaches (Rogers, 1951; Stober, 2006) that empathetic listening builds trust, establishes rapport, and encourages reflective thought.

When we practice deep listening, we work to reside in the moment, focus intently on the instructor's verbal and nonverbal cues, and listen without jumping to conclusions. To maintain a focus on the instructor, we advise developers to try not to spend time contemplating whether the instructor is "right" or "wrong," focusing on the next question to ask, or thinking about how they would solve the instructor's problems. Instead, pay attention to what the speaker is communicating verbally and nonverbally, and consider which topics the instructor shows most enthusiasm about, which points he or she avoids, or how gestures or facial expressions reveal unspoken values or beliefs about teaching and learning. By occasionally summarizing and paraphrasing the instructor's emotions and ideas, developers can check comprehension and reflect back the instructor's feelings and values in their responses. One instructor described the value of being deeply listened to this way: "The consultation was immeasurably helpful. I especially appreciated how you listened to and paraphrased back my comments and let me figure things out by talking them through. ... I gain so much when I am given the space to do that."

Deep listening requires becoming comfortable with the silences and pauses necessary for the speaker to talk it through. Purposefully extending the wait time in consultations, as in the classroom, models thoughtfulness and restraint while encouraging a higher level of critical response. Based on the research on productive wait time in classroom discussion (Rowe, 1972), 
we recommend pausing at least three to five seconds after asking a question and before responding to the instructor's comments. To avoid immediate responses, developers can examine their motives for speaking by briefly answering the following questions: Why am I offering a suggestion? To whom is this comment really directed? Who will benefit from it? In short, deep listening means listening attentively to the speaker with the intention to understand rather than to judge, react, or instantly solve the problem. Being mindful of our level of listening, stray thoughts, and motivations to speak can help keep the focus of the consultation on the instructor.

\section{Asking Powerful Questions}

Deep listening promotes feelings of trust and a safe, supportive atmosphere. However, empathetic listening and descriptive feedback alone do not add new ideas or provoke change (Border, 1997). Combining deep listening with a series of powerful, thought-provoking questions can help interrupt the rush to premature judgment or action and slow the pace to provide a space for reflection.

Questions lie at the heart of everything we do. They are "fundamental for gathering information, building and maintaining relationships, learning, thinking clearly, creatively, and critically, making requests, and initiating action" (Goldberg Adams, 2004, p. 2). Our actions and our understanding of self and others spring from our questions. Postman (1995) explains, "Everything we know has its origins in questions. Questions, we might say, are the principal intellectual instruments available to human beings" (p. 172). Powerful questions can alter subsequent thinking and behavior; however, some intellectual instruments are better suited for promoting critical thought and reflection than others.

In workshops about consultation techniques that we facilitate, we end a listening exercise by discussing the types of questions that arose during it. This conversation helps participants become more aware of the kinds of questions they ask. Did they ask for greater clarification or elaboration out of general curiosity, or because they were relating it to personal experiences? As developers ask questions during individual consultations, it is helpful to consider motives by mentally answering the following: What will the question accomplish? What is its purpose? Whose needs does it serve?

The first category, consultant-focused questions, springs from the same tendencies as self-focused listening: these questions are motivated by the consultant's autobiography or interests, and they interrupt or distract the speaker from his or her concerns. Solution-focused questions can have negative effects: leading the speaker toward a particular answer, provoking 
the speaker through a veiled challenge or implied judgment, or closing down thought by having only one or two possible answers. In consultation with an instructor struggling with student attendance, for instance, asking, "Do you take attendance?" implies a solution connected to this act. Because they focus primarily on information gathering or either-or thinking, consultant- and solution-focused questions are not often transformative.

We refer to the third category of instructor-focused questions, which includes questions focused on the speaker, as powerful questions. Powerful questions, such as those in Exhibits 8.1 and 8.2, ask the instructor to think about something to which she or he does not know the answer beforehand. In consultations, we find these types of questions often elicit such responses as "I don't know" or "I've never thought about that." Powerful, open-ended questions produce more significant learning (Brookfield \& Preskill, 2009) and can lead to higher levels of engagement, thought, resourcefulness, and follow-through. They can benefit both developer and instructor by fostering curiosity, provoking thought, or invoking new possibilities or perspectives. Asking thoughtful questions can promote trust by demonstrating the developer's interest in the instructor's ideas and learning by allowing the instructor to think out loud.

Powerful questions allow the instructor to gather information, organize thoughts, clarify problems, discover novel possibilities; and unlock creativity. In short, they can "shake people out of their conventional thinking, deepen understanding, and help lead the way toward envisioning new possibilities" (Brookfield \& Preskill, 2009, p. 127). Because questions by their very nature call for answers, they also initiate movement, propelling the instructor toward decisions and actions to meet short- and long-term goals. Powerful questions can clarify the situation, including the perceived and underlying issues, create possibilities, shift perspectives (Exhibit 8.1), and prompt future action (Exhibit 8.2).

Exhibit 8.r Examples of Powerful Questions That Clarify and Create Possibility

\section{Questions That Clarify}

- What happened? What are the facts of the situation?

- What do you think is really going on? What's really at stake here?

- What would you like to see happen? 
- What is working well? What is not?

- Which of your values are you honoring in this situation? Which are you not honoring?

- What is really important to you about this?

- Why does it matter to you?

\section{Questions That Create Possibility}

- What is another perspective you could have about this?

- What do you want to happen? What is really important to you about this?

- In what ways are you stuck? What would it take to get unstuck?

- What are potential risks? Benefits?

- What other options can you think of? Would you like to brainstorm ideas?

A consultation with John (not his real name) highlights the collaborative nature of this process. After several meetings revealed that John's attempts to redesign a course failed to move beyond the coverage model, Michael decided to take a new approach. Rather than telling John that his approach was less likely to produce significant learning experiences, he asked a question to elicit new possibilities: "What are the big questions underlying all this content that first excited you about the subject?" Reflecting on his own passion for the subject from a different perspective transformed John's understanding of course design. As a result, he reorganized his course around a series of big questions and let his goals, rather than his concerns about coverage, guide his decisions about content and assignments.

\section{Prompting Action}

The third component in the coaching-based framework focuses on one particular category of powerful questions: those that elicit commitments to future action. As a question-centered practice, coaching is grounded in forward-moving change: "Questions (including requests) initiate behavior or action, be it mental or physical. Questions focus and direct attention and energy" (Goldberg, 1998, p. 7). By being aware of the ways questions can initiate behavior or action, a developer can prompt instructors to take meaningful and significant action and discuss ways to follow through on them. Exhibit 8.2 offers suggested questions to prompt instructors to set realistic goals, identify what actions they will take when, and think about how they will assess whether they are meeting their goals. 


\section{Exhibit 8.2. Examples of Powerful Questions That Prompt Action}

\section{Questions That Prompt Goal Setting}

- What would you like to get out of this consultation? What questions about teaching are you trying to answer?

- What specifically are you going to do? When are you going to do it?

- What obstacles might you meet along the way?

- What will be the hardest part for you in taking this action?

- What support do you need? How and when will you get this support?

- What first steps will you take?

\section{Questions That Prompt Assessment}

- How will you know that you are making progress toward these goals?

- How will you measure success?

- How will you know this made a difference?

- How can I be of help to you? What other resources can I provide?

By encouraging goal setting and concrete actions, the final component of the coaching framework allows the instructor to define and initiate change and to determine how she or he will measure the effects of change. At this point in the consultation, offering additional resources, ideas, and a range of possible best practices applicable to the situation can help the instructor devise a plan of action. During a collaborative discussion, the instructor can select options based on his or her values, short- and long-term goals, energy, and time.

Keeping the end in mind can help developers guide the first part of the consultation as we help the instructor clarify short- and long-term goals with an eye toward translating these into specific actions. Consulting with Karen about improving the lecture, Deandra began with a clarifying question: "What do the teacher-student and student-student interactions currently look like in your lectures?" Next she asked Karen a question to elicit new possibilities: "What would these interactions look like in your ideal class?" Then together, they explored ways Karen might realize these goals ("What kinds of learning activities would lead to the types of change you are interested in?") and respond to challenges to those goals ("What if students resist being asked to take a more active role in class?"). Shifting focus, Deandra asked Karen which of these strategies best matched her 
goals and the course content; then they identified small, concrete steps in response to the question: "What is the first thing you plan to do to engage the students?" As a result, Karen left with specific ideas in mind. After the lecture, Karen assessed student engagement, reporting that "things went well. They [students] applauded at the end and there was a lot of good class discussion. I don't usually get applause until the last day [of the semester-an institutional tradition]."

\section{The Role of Data Collection}

Data management and analysis play an important role in the coachingbased framework. (For more on specific data collection methods, see Brinko \& Menges, 1997; Gillespie et al., 2002; Lewis \& Lunde, 2001.) When combined with data collected by the instructor or developer, powerful questions can engage the instructor in reflective practice, a marker of professional self-development (Brookfield, 1995; Schön, 1983) and transformative learning (Cranton, 2006). Because questions serve as engines of knowledge creation and the language of our questions helps structure reality, how we frame a question determines the kind of answers we receive. Powerful questions ask the instructor to examine the assumptions underlying his or her teaching, compare these assumptions with data the instructor or developer has collected, and commit to future actions that better align those beliefs and practices.

Using the framework also means providing and analyzing data in a value-neutral manner, avoiding praise or criticism. Discussing an in-class observation, for example, a developer might comment: "You asked five questions in the first ten minutes of class. Four of these questions asked students to recall information. One asked them to apply it to a novel situation." Developers can then nonjudgmentally ask the instructor to consider what the data reveal and what kinds of responses they warrant. In all cases, the wording matters: carefully formulated questions require the instructor to process information cognitively in different ways (Costa \& Garmston, 1994). Questions that ask "Who? What? Where?" help clarify the situation by asking the instructor to gather and recall information, activities among the lower levels of Bloom's taxonomy (Krathwohl, 2002). Questions starting with, "What?" typically require more inference and analysis. And questions such as, "How do you think this would be different if . . .?" or, "What are you going to do?" ask the instructor to hypothesize, synthesize, or apply ideas in new ways. Because they imply the need to justify one's actions, questions beginning "Why did you ... ?" are better avoided. Reframing "why" questions to ask, "What was your 
motivation to do X?" or "How did X accomplish your goals?" makes them more powerful. (For more examples of ways that question syntax can affect the cognitive processes of the instructor, see Cranton, 2006; Costa \& Garmston, 1994; or Auerbach, 2006.)

\section{Important Considerations}

Occasionally instructional consultations touch on areas of personal and professional identity that threaten to cross the line between consulting and therapy. This is particularly true for the coaching framework because it relies on empathetic communication and a question-centered orientation, both hallmarks of counseling practice (Goldberg, 1998). As with any other consultation, developers should remain aware of and maintain professional boundaries, particularly if they do not have counseling training. If the consultation begins to take on a therapeutic quality, encourage the instructor to seek other resources.

Paying attention to the instructor's nonverbal or verbal cues can also reveal whether the instructor is comfortable with the method. Cultural, developmental, or personal differences may require different modes of interaction. In some cultures, for example, asking direct questions might be perceived as rude, or deep listening may be misinterpreted. The developmental stage of the instructor can also affect the consultation (Wergin, Mason, \& Munson, 1976); novice instructors who have fewer strategies to call on may prefer that developers assume the role of expert rather than facilitator and may expect answers or quick tips and a less collaborative consultation.

In all cases, we recommend being explicit about the framework. We typically start a consultation by explaining that our consultations rely on open-ended questions and deep listening and that we see our roles as facilitators (Border, 1997). If the instructor expresses or demonstrates discomfort with the process after this explanation or at any point during the consultation, we shift to a different consultative style or allow the instructor to choose whether to continue (Brinko, 1997).

\section{Conclusion}

Taken together, deep listening, asking powerful questions, and prompting action enable us to act as agents of positive change during consultations, in alignment with the values and guidelines of our profession (Professional and Organizational Development Network in Higher Education, 2009). The empathetic quality of deep listening allows the developer to 
be receptive to different styles and approaches to teaching while respecting others' rights to hold values, attitudes, and opinions different from his or her own. The question-centered method and self-awareness it requires encourages instructor and developer reflective practice and can empower client action, based on the client's needs and motivations. Coaching allows developers to provide formative feedback to instructors in a nonjudgmental environment. In short, developers using coaching methods find themselves asking good questions that help the instructor unlock and act on what is already there.

\section{REFERENCES}

Auerbach, J. (2006). Cognitive coaching. In D. Stober \& A. M. Grant (Eds.), Evidence based coaching handbook (pp. 103-128). Hoboken, NJ: Wiley. Border, L. (1997). Identifying and assessing your consultation style. In K. T. Brinko \& R. J. Menges (Eds.), Practically speaking: A sourcebook for instructional consultants in higher education (pp. 211-216). Stillwater, OK: New Forums Press.

Brinko, K. T. (1993). The practice of giving feedback to improve reaching: What is effective? Journal of Higher Education, 64(5), 574-593.

Brinko, K. T. (1997). The interactions of teaching improvement. In K. T. Brinko \& R. J. Menges (Eds.), Practically speaking: A sourcebook for instructional consultants in higher education (pp. 3-8). Stillwater, OK: New Forums Press.

Brinko, K. T., \& Menges, R. J. (Eds.). (1997). Practically speaking: A sourcebook for instructional consultants in higher education. Stillwater, $\mathrm{OK}$ : New Forums Press.

Brookfield, S. (1986). Understanding and facilitating adult learning: A comprehensive analysis of principles and effective practices. San Francisco: Jossey-Bass.

Brookfield, S. (1995). Becoming a critically reflective teacher. San Francisco: Jossey-Bass.

Brookfield, S., \& Preskill, S. (2009). Learning as a way of leading: Lessons from the struggle for social justice. San Francisco: Jossey-Bass.

Costa, A. L., \& Garmston, R. L. (1994). Cognitive coaching: A foundation for Renaissance schools. Norwood, MA: Christopher-Gordon.

Cranton, P. (2006). Understanding and promoting transformative learning: A guide for educators of adults. San Francisco: Jossey-Bass.

Garmston, R., \& Wellman, B. (1999). The adaptive school: A sourcebook for developing collaborative groups. Norwood, MA:

Christopher-Gordon. 
Gillespie, K. H., Hilsen, L. R., \& Wadsworth, E. C. (Eds.). (2002). A guide to faculty development: Practical advice, examples, and resources. San Francisco: Jossey-Bass/Anker.

Goldberg, M. C. (1998). The art of questions: A guide to short-term questioncentered therapy. Hoboken, $\mathrm{NJ}$ : Wiley.

Goldberg Adams, M. C. (2004). Expert question asking: The engine of successful coaching. Institute for Inquiring Leadership. Retrieved from www .inquiryinc.com/knowledge/pdf/ExpertQuesAsking.pdf

Knapper, C., \& Piccinin, S. (1999). Consulting about teaching: An overview. In C. Knapper \& S. Piccinin (Eds.), New directions for teaching and learning: No. 79. Using consultants to improve teaching (pp. 3-8). San Francisco: Jossey-Bass.

Krathwohl, D. (2002). A revision of Bloom's taxonomy: An overview. Theory into Practice, 41(4), 212-218.

Lewis, K. G. (2002). The process of individual consultations. In K. H. Gillespie, L. R. Hilsen, \& E. C. Wadsworth (Eds.), A guide to faculty development: Practical advice, examples, and resources (pp. 59-73). San Francisco: Jossey-Bass/Anker.

Lewis, K. G., \& Lunde, J.T.P. (Eds.). (2001). Face to face: A sourcebook of instructional consultation techniques for faculty/instructional developers. Stillwater, OK: New Forums Press.

Postman, N. (1995). The end of education. New York: Vintage.

Professional and Organizational Development Network in Higher Education. (2009). Ethical guidelines for educational developers. Retrieved from www.podnetwork.org/faculty_development/ethicalguidelines.htm

Rhoedick, S. (2006). Using the helping process to strengthen our consultation skills. Paper presented at the 31st annual meeting of the Professional and Organizational Development Network in Higher Education, Portland, OR.

Rogers, C. (1951). Client-centered therapy: Its current practice, implications, and theory. Boston: Houghton Mifflin.

Rowe, M. B. (1972). Wait time and rewards as instructional variables: Their influence in language, logic, and fate control. Paper presented at the National Association for Research in Science Teaching, Chicago. (ERIC Document Reproduction Service No. ED061103)

Schön, D. A. (1983). The reflective practitioner: How professionals think in action. New York: Basic Books.

Stober, D. R. (2006). Coaching from the humanistic perspective. In D. R. Stober \& A. M. Grant (Eds.), Evidence based coaching handbook (pp. 17-50). Hoboken, NJ: Wiley.

Stober, D. R., \& Grant, A. M. (Eds.). (2006). Evidence based coaching handbook. Hoboken, NJ: Wiley. 
Svinicki, M. D. (2004). Learning and motivation in the postsecondary classroom. San Francisco: Jossey-Bass/Anker.

Theall, M. (2001). Thinking about motivation: Some issues for instructional consultants. In K. G. Lewis \& J.T.P. Lunde (Eds.), Face to face: A sourcebook of instructional consultation techniques for faculty/instructional developers (pp. 77-91). Stillwater, OK: New Forums Press.

Tiberius, R., Tipping, J., \& Smith, R. (1997). Developmental stages of an educational consultant: Theoretical perspective. In K. T. Brinko \& R. J. Menges (Eds.), Practically speaking: A sourcebook for instructional consultants in higher education (pp. 217-221). Stillwater, OK: New Forums Press.

Wergin, J. F., Mason, J., \& Munson, P. J. (1976). The practice of faculty development: An experience-derived model. Journal of Higher Education, 47(3), 289-308. 